\title{
Yapılarda kullanılan malzemelerden yayılan doğal radyasyonun araştırılmasına yönelik çalışmalar
}

\author{
Ali AŞKIN *,1, Murat DAL ${ }^{2}$ \\ ${ }^{1}$ Munzur Üniversitesi Mühendislik Fakültesi Mekatronik Mühendisliği Bölümü \\ ${ }^{2}$ Munzur Üniversitesi Mühendislik Fakültesi İnşaat Mühendisliği Bölümü \\ Geliş Tarihi (Recived Date): 04.10.2017 \\ Kabul Tarihi (Accepted Date): 06.03.2018
}

\section{Özet}

$\mathrm{Bu}$ derlemede, çeşitli yapı malzemelerinde var olan ${ }^{226} \mathrm{Ra},{ }^{232} \mathrm{Th},{ }^{40} \mathrm{~K}$ radyoaktif izotoplarından yayılan gama radyasyonun aktivitesinin ve bu aktivitelere bağll olan radyum eşdeğer aktivitesi, gama ve alfa indeksi, soğurulan gama doz oranı ile iç ve dış risk indeksleri gibi radyolojik parametrelerinin belirlenmesi amacıyla Türkiye'de ve diğer ülkelerde yapılmış araştırmalar ve sonuçları incelenerek okuyucuların dikkatine sunulmuştur. Yapılan çalışmaların genelinde granit ve kum örneklerindeki doğal radyoaktivite diğer malzemelere oranla daha yüksek bulunmuştur. Aktivitesi yüksek bulunan bazı çimento örneklerinde, yüksek radyoaktivtenin kaynağının çimentoda katkı malzemesi olarak kullanılan kül'den kaynaklandığ belirtilmiştir. Bu konuda yapılan çalışmaların sayıları ve elde edilen sonuçlar değerlendirildiğinde, yapı malzemelerinden yayılan doğal radyoaktivitenin belirlenmesinin uzun vadede insan sağlı̆̆ının korunmasına önemli katklları olacă̆ı görülmektedir.

Anahtar kelimeler: Doğal radyoaktivite, yapı malzemesi, radyolojik parametre.

\section{Studies on the investigation of natural radiation emitted from building materials}

\begin{abstract}
* Ali AŞKIN, aliaskin@munzur.edu.tr, http://orcid.org/0000-0001-8571-3680

Murat DAL, muratdal@munzur.edu.tr, http://orcid.org/0000-0001-5330-1868
\end{abstract}

In this rewiev, studies performed in Turkey and in abroad in order to determine the gamma activities of the ${ }^{226} \mathrm{Ra},{ }^{232} \mathrm{Th},{ }^{40} \mathrm{~K}$ isotopes existed in the various building materials and the radiological parameters depending on the activities such as, radium equivalent activity, gamma and alpha indexes, absorbed ratio of gamma dose, internal and external hazard indexes, are investigated and their results are summarized for the 
readers. In the performed studies, the radioactivities of the granite and sand samples are found to be higher than the other materials. In some cement specimens with high activity, it was reported that the source of high radioactivity originates from the ash, which is commonly used as an additive material in cement. When the number of studies and their results are considered, it is understood that the determination of natural radioactivity emitted from building materials will be very important for the protection of human health in a long term.

Keywords: Natural radioactivity, building material, radiological parameter.

\section{Giriş}

Doğada en yaygın bulunan radyoaktif elementler ${ }^{238} \mathrm{U},{ }^{232} \mathrm{Th}$ ve ${ }^{40} \mathrm{~K}$ 'dur. ${ }^{238} \mathrm{U}$ 'in yarılanma süresi $4.4 \times 10^{9}$ yıl ve doğada $\% 99$ oranında bulunur. ${ }^{232}{ }^{T h}$ ' nin yarılanma süresi $1.4 \times 10^{10}$ yıl ve doğada bulunma oranı \%99' dan fazladır. Her iki radyoaktif element bozunma zincirine sahip olup, bu elementlerin bozunmasiyla yeni radyoaktif elementler açığa çıkar. ${ }^{238} \mathrm{U}$ bozunma zincirinde oluşan ${ }^{226} \mathrm{Ra}$ ' dan sonrası radyolojik olarak önemli olması nedeniyle araştırmalarda elde edilen sonuçların sunumunda ${ }^{238} \mathrm{U}$ ' in yerine ${ }^{226} \mathrm{Ra}$ gösterilmektedir. ${ }^{40} \mathrm{~K}$ ' in yarılanma ömrü $1.3 \times 10^{9}$ y1l ve doğada bulunma oranı \%0.012' dir. $\mathrm{Bu}$ elementlerin yarılanma ömürleri göz önüne alındığında, dünyanın her yerinde doğada ve çevrede bu elementler bulunmaktadır. ${ }^{238} \mathrm{U}$ ve ${ }^{232} \mathrm{Th}$ en önemli gama radyasyonu yayıcı elementlerden olup, dünya nüfusunun maruz kaldığ yıllık doğal radyasyon dozunun \%83' ü bu elementler, \%16 ise ${ }^{40} \mathrm{~K}$ nedeniyledir $[1,2]$. Yapı inşasında kullanılan malzemelerin büyük çoğunluğunun doğal kaynaklardan üretilmesi nedeniyle bu elementlerin yapı malzemelerinde bulunma oranlarının tespit edilmesi ve insan sağlığına olan etkilerinin araştırılması kritik öneme sahiptir. Bu malzemelerden yayılan aktivitenin düşük olması bile iç ve dış radyasyona maruz kalınmasına neden olur. Dış radyasyon; genellikle gama 1şıması kaynaklı olup uranyum, toryum bozunma zincirinden ve potasyumun bozunmasıyla açığa çıkar. Yapı malzemelerinden yayılan gama işınlarının uzun mesafelere gidebilmesi nedeniyle insanlar bu radyasyona sürekli maruz kalmakta ve uzun vadede çeşitli sağlık risklerine neden olabilmektedir. İç radyasyon, genellikle uranyum bozunma zincirinde açığa çıkan kısa yarılanma ömürlü ${ }^{222} \mathrm{Rn}$ gazının havaya karışması sonucu solunum yollarına ve akciğerlere ulaşması ile meydana gelmektedir.

Tablo 1. Radyolojik parametrelerin uluslararası kabul edilmiş limit değerleri.

\begin{tabular}{ccc}
\hline Radyolojik parametre & Limit değeri & Referans \\
\hline Radyum eşdeğer aktivitesi $\left(\mathrm{Ra}_{\mathrm{e}}\right)$ & $\mathrm{Ra}_{\mathrm{es}} \leq 370$ Bq.kg-1 & {$[6,7]$} \\
Gama indeksi $\left(\mathrm{I}_{\gamma}\right)$ & $\mathrm{I}_{\gamma} \leq 1$ & {$[6,8]$} \\
Alfa indeksi $\left(\mathrm{I}_{\alpha}\right)$ & $\mathrm{I}_{\alpha} \leq 1$ & {$[6,8]$} \\
Diş risk indeksi $\left(\mathrm{H}_{\mathrm{ex}}\right)$ & $\mathrm{H}_{\mathrm{ex}} \leq 1$ & {$[6,8]$} \\
İç risk indeksi $\left(\mathrm{H}_{\text {in }}\right)$ & $\mathrm{H}_{\text {in }} \leq 1$ & {$[6,8]$} \\
\hline
\end{tabular}

Yapı malzemelerinden yayılan yüksek dozda iç ve dış radyoaktiviteye maruz kalınması hücre ve DNA yapısına zarar vererek, radyasyon kaynaklı kanser, kronik akciğer rahatsızlıkları, kan ve kemik iliği rahatsızlıklarına sebep olduğu bilinmektedir $[3,4,5]$. Yapı malzemeleri içinde doğal olarak bulunan ${ }^{226} \mathrm{Ra},{ }^{232} \mathrm{Ra},{ }^{40} \mathrm{~K}$ radyoaktif izotoplarının aktivite değerlerinin insan sağlığına etkilerini değerlendirebilmek amacıyla radyum eşdeğer aktivitesi ( $\left(\mathrm{R}_{\mathrm{ess}}\right)$, soğurulan doz oranı ve yıllık etkin doz (D), gama indeksi ( $\left.\mathrm{I}_{\gamma}\right)$, 
alfa indeksi $\left(\mathrm{I}_{\alpha}\right)$, iç ve diş risk indeksleri $\left(\mathrm{H}_{\mathrm{in}}, \mathrm{H}_{\mathrm{ex}}\right)$ gibi farklı radyolojik parametreler tanımlanmıştır. Tablo 1'de radyolojik parametrelerin limit değerleri özetlenmiş, bu parametrelerin hesapanması için gerekli olan formüller bölüm 2.1'de verilmektedir.

Yapı malzemelerinden yayılan doğal radyasyonun miktarının belirlenmesi konusunda dünya genelinde yapılmış çok sayıda bilimsel çalışma bulunmaktadır. Bu derlemede amaçlanan, Türkiye' de ve diğer ülkelerde bu alanda yapılmış çalışmaları özetleyerek, elde edilen sonuçları değerlendirmektir.

\section{Materyal ve yöntem}

$\mathrm{Bu}$ çalışmada yapı malzemelerinden yayılan radyasyonun insan sağlığına etkilerinin araştırılması için ulusal ve uluslararası dergilerde yayınlanan makaleler incelenmiştir.

Yapı malzemelerinin radyoaktivite değerlerinin belirlenmesi çalışmalarında, gama aktivite ölçümlerinde yüksek hassasiyete sahip yüksek saflıklı Germanyum dedektörü (High Purity Germanium (HPGe)), bazı çalışmalarda ise NaI(Tl) sintilasyon dedektörü kullanılmaktadır.

Gama spektroskopi sistemi malzemelerin radyoaktif olup olmadığının belirlenmesinde etkili bir yöntemdir [9].

Numunelere ait net spektrumun analizinde ${ }^{238} \mathrm{U},{ }^{232} \mathrm{Th}$ ve ${ }^{40} \mathrm{~K}$ 'ya ait karakteristik pik'ler, bu piklerin altında kalan alan (karakteristik pike ait sayım sayısı) ile dedektör kalibrasyonundan elde edilen tespit verim değerleri kullanılır. Aşağıda verilen formüller ölçümü yapılan numuneye ait aktivite değerinin hesaplanmasına yönelik olup, bulunan aktivite değerlerine ait hataların hesaplanması için kullanılacak formüller verilmemiştir. Dedektörün tespit (sayım) verimini belirlemek için $[10,11,12]$;

$\varepsilon_{\gamma}=\frac{N_{n e t}}{A \cdot I_{g} \cdot t}$

eşitliğinden faydalanılır. Bu eşitlikde, $\varepsilon_{\gamma}$ dedektör tespit verimini, $N_{\text {net }}$ kalibrasyon spektrumundaki radyoaktif bozunmaya ait karakteristik pik alanını (pik için sayım miktarı), $A$ kalibrayon kaynağı aktivitesini (Becquerel, $B q$ ),$I_{g}$ radyoaktif kaynaktan yayılan farklı enerjili fotonlar için gama yayılma oranını, $t$ kalibrasyon kaynağı ile ölçüm zamanını (saniye) belirtmektedir.

Gama karakteristik piklerinin altında kalan sayım adedi ve dedektör tespit veriminin kullanılması ile aktiviteyi hesaplamak için $[10,11,12]$;

$\mathrm{SA}=\frac{\mathrm{N}_{\mathrm{S}}}{\varepsilon_{\gamma} \cdot \mathrm{I}_{\mathrm{g}} \cdot \mathrm{t} \cdot \mathrm{m}}$

$\mathrm{Bu}$ eşitlikde, $S A$ ölçümü yapılan numunenin spesifik aktivitesi $\left(\mathrm{Bq}^{\mathrm{kg}} \mathrm{kg}^{-1}\right), \quad \mathrm{N}_{\mathrm{S}}$ background çıkartılmış ölçüm spektrumunda ${ }^{238} \mathrm{U},{ }^{232} \mathrm{Th}$ ve ${ }^{40} \mathrm{~K}$ ' a ait karakteristik piklerin altında kalan alan (sözkonusu pik içindeki sayım miktarı), $\varepsilon_{\gamma}$ kalibrasyondan elde edilecek tespit vermini, $I_{g}$ aynı radyoaktif kaynaktan yayılan farklı enerjili fotonlar için gama bozunma oranını, $t$ numune ölçüm zamanını (saniye) belirtmektedir. 
${ }^{226} \mathrm{Ra}\left({ }^{238} \mathrm{U}\right)$ aktivitesi $\mathrm{A}_{\mathrm{Ra}}$ ile ${ }^{232} \mathrm{Th}$ aktivitesi $\mathrm{A}_{\mathrm{Th}}$ ile ${ }^{40} \mathrm{~K}$ aktivitesi ise $\mathrm{A}_{\mathrm{K}}$ ile gösterilmiș ve $\mathrm{Bq} \cdot \mathrm{kg}^{-1}$ (Becquerel $/ \mathrm{kg}$ ) biriminde sunulmuştur. Bulunan aktivite değerleri kullanılarak radyum eșdeğer aktivitesi, gama ve alfa indeksleri, soğurulan gama doz oraları ve iç ve dış risk indeksleri gibi radyolojik parametreler hesaplanır.

\subsection{Radyum Radyum eşdeğer aktivitesi ( $\left.R a_{e q}\right)$}

Radyum eşdeğer aktivitesi (Bq. $\mathrm{kg}^{-1}$ ), yapı malzemeleri içindeki radyoaktif elementlerin eşit dağılmaması nedeniyle ${ }^{226} \mathrm{Ra},{ }^{232} \mathrm{Th}$ ve ${ }^{40} \mathrm{~K}$ aktivite değerlerini ve bunların radyasyon riskini göstermek amacıyla kullanılan ortak bir radyolojik parametredir. $\mathrm{Bu}$ parametrenin hesaplanması aşağıda verilen formül ile yapılabilir [12,10,7].

$R a_{e q}=A_{R a}+1.43 * A_{T h}+0.077 A_{K}$

\subsection{So ğurulan doz oranı ve yillı etkin doz (D)}

${ }^{226} \mathrm{Ra},{ }^{232} \mathrm{Th}$ ve ${ }^{40} \mathrm{~K}$ aktivitesine bağlı olarak yayılan gama 1şınının yapı dışındaki ( $\mathrm{D}_{\text {out}}$ ) ve yapı içindeki $\left(D_{\text {in }}\right)\left(n G y \cdot h^{-1}\right)$ soğurulma oranını bulmak ve gama soğurulma dozunu hesaplamak için aşağıda verilen eşitlik kullanılır [12,10,7].

$D_{\text {out }}=0.427 * A_{R a}+0.662 * A_{T h}+0.0432 A_{K}$

Yapı içinde soğurulan doz oranı dışarıdan fazla olması nedeniyle iç soğurma oranını bulmak için;

$D_{\text {in }}=1.4 * D_{\text {out }}$

eşitliğinden faydalanılır. Yıllık etkin doz miktarı $\left(E_{\text {in }}\right)\left(m S v \cdot y^{-1}\right) \mathrm{n}$ hesaplamak için $[7,14]$;

$E_{\text {in }}=D_{\text {in }} * 8760 h * 0.7 S v y^{-1} * 0.8 * 10^{-6}$

eşitliği kullanılır.

\subsection{Gama indeksi $\left(I_{\gamma}\right)$}

Yap1 malzemelerindeki güvenlik gereksinimlerinin avrupa komisyonu tarafından tavsiye edilen gereksinmeleri karşıladığına karar verebilmek için gama indeksinin $\left(I_{\gamma}\right)$ hesaplanması gereklidir [8].

$I_{\gamma}=\frac{A_{R a}}{300}+\frac{A_{T h}}{200}+\frac{A_{K}}{3000}$

$I_{\gamma} \leq 1$ olması soğurulan yıllık gama dozunun $1 \mathrm{mSv} \cdot \mathrm{y}^{-1}$ 'a eşit veya küçük olmasına $I_{\gamma} \leq$ 0.5 olması ise yıllık soğurulan gama dozunun $0.3 \mathrm{mSv} \cdot \mathrm{y}^{-1}$ ' a eşit veya küçük olduğunu gösterir. Bu dozun $1 \mathrm{mSv} \cdot \mathrm{y}^{-1}$ dan az olması beklenir $[6,8]$.

\subsection{Alfa indeksi $\left(I_{a}\right)$}

Alfa indeksi $\left(\mathrm{I}_{\alpha}\right)$ yapı malzemelerinden salınan radon gazının solunmasına bağlı olarak maruz kalınan radyasyonun değerlendirilmesinde kullanılan indeksdir.

$$
I_{\alpha}=\frac{A_{R a}}{200}
$$


ile bu indeksin değeri hesaplanabilir $[15,16]$. Yapı malzemeleri için güvenli $\mathrm{I}_{\alpha}$ değeri 1 den az olmalıdır. Bu durumda ${ }^{226} \mathrm{Ra}$ aktivitesi $200 \mathrm{~Bq} \cdot \mathrm{kg}^{-1}$ dan küçük olması gerekmektedir $[6,8]$.

\section{5. İc ve diş risk indeksi $\left(H_{\text {in }}, H_{e x}\right)$}

Yapı malzemelerinden kaynaklanan dış radyolojik riskin belirlenmesi için dış risk indeksi $\left(\mathrm{H}_{\mathrm{ex}}\right)$ kullanılır [17].

$H_{e x}=\frac{A_{R a}}{370}+\frac{A_{T h}}{259}+\frac{A_{k}}{4810}$

Ekonomik İşbirliği ve Kalkınma Örgütü (Organisation for Economic Co-operation and Development (OECD)) tarafından belirlenen ve uluslararası kabul edilen güvenli $\mathrm{H}_{\mathrm{ex}}$ değeri, $\mathrm{H}_{\mathrm{ex}} \leq 1$ olmalıdır. Yapı malzemelerinden yayılan dış radyasyona yıllık maruz kalma limiti $1.5 \mathrm{mSv} \cdot \mathrm{y}^{-1}$ olarak belirlenmişdir [6,8].

Dış radyasyona ek olarak, radon ve radonun bozunmasıyla oluşan kısa ömürlü izotoplarda solunum organları için risklidir. Yapı içinde, yapı malzemelrinden salınan radon gazına maruz kalma miktarının belirlenmesinde iç risk indeksi $\left(\mathrm{H}_{\text {in }}\right)$ kullanılır [17].

$H_{\text {in }}=\frac{A_{R a}}{185}+\frac{A_{T h}}{259}+\frac{A_{K}}{4810}$

OECD tarafından belirlenenerek uluslararası kabul edilen güvenli $H_{\text {in }}$ değeri 1 ' in altında olmalıdır $[6,8]$.

\section{Literatür analizi}

Yapı inşasında kullanılan malzemelerin radyoaktivitelerinin ölçülmesi amacıyla yapılmış ve uluslararası literatürde yayınlanmış çalışmaların başlıkları, yayın tarihleri ve özetleri bu kısımda sunulmuştur. Literatür analiz kısmı Türkiye' de yapılmış çalışmalar ve yurt dışı çalışmaları olarak iki alt başlıkta, yayının adı, yayınlanma yılı ile birlikte verilerek özetlenmişdir. Yapılan çalışmaların aktivite sonuçları karşılaştırma yapılabilmesi amacıyla Değerlendirme ve Sonuç bölümünde Tablo 3' de sunulmuştur.

\subsection{Yurtdışında yapılmış çeşitli çalışmalar ve sonuçları}

- "Concentrations of 226Ra, 232Th and 40K in industrial kaolinized granite" : Bu araştırmada, Bosna Hersek' den Sırbistan'a ithal edilen 6 farklı kaolinli granit numunesinin doğal radyoaktivite değerleri HPGe dedektörü ile ölçülmüştür. Aktivite değerlerine bağlı olarak hesaplan radyolojik indekslerden gama indeksinin 2'den büyük çıktığını, yıllık doz limitini $\left(0.3 \mathrm{mSv}^{-1}\right)$ aştı̆̆ını, soğurulan doz oranı ile yıllık etkin doz oranının limit değerlerin altında kaldığını yayınlamışlardır [18].

- "Radiological impact assessment to the environment due to waste from disposal of porcelain": $\mathrm{Bu}$ makalede, Misır'da üretilen ve ithal edilen porselenlerin, kontrolsüz olarak çevreye atılmaları sonucunda ortaya çıkan ${ }^{226} \mathrm{Ra},{ }^{232} \mathrm{Th}$ ve ${ }^{40} \mathrm{~K}$ aktiviteleri HPGe dedektörü kullanılarak araştırılmıştır. Araştırma sonucunda, Misırda üretilen porselenin ortalama aktivite değerleri ${ }^{226} \mathrm{Ra}$ için $208.2 \mathrm{~Bq} \cdot \mathrm{kg}^{-1},{ }^{232} \mathrm{Th}$ için 84.9 Bq. $\mathrm{kg}^{-1}$ ve ${ }^{40} \mathrm{~K}$ için $1033.6 \mathrm{~Bq} \cdot \mathrm{kg}^{-1}$ olarak bulunmuştur. İthal porselen numunelerinin ortalama aktivite değerleri ${ }^{226} \mathrm{Ra}$ için $240.5 \mathrm{~Bq} \cdot \mathrm{kg}^{-1},{ }^{232} \mathrm{Th}$ için 115.7 
Bq.kg-1 ve ${ }^{40} \mathrm{~K}$ için 1312.4 Bq.kg ${ }^{-1}$ olarak yayınlanmıştır. Her iki porselen çeşidinin indeks değerlerinin önerilen değerlerden yüksek olması nedeniyle insan sağlığı için önemli bir risk oluşturdukları belirtilmiştir [19].

- "Naturally occurring radioactivity in some Swedish concretes and their constituents - Assessment by using I-index and dose-model": Bu çalışmada, yapılarda kullanılan agreganın ve bu agregaların katkı olarak kullanıldığı betonun doğal radyoaktivite ölçümleri iki farklı doz modeliyle ve HPGe dedektörü ile alınan ölçümler kullanılarak yapılmıştır [20].

- "Assessment of Natural Radioactivity Levels and Potential Radiological Risks of Common Building Materials Used in Bangladeshi Dwellings" : Bu makalede, Bangladeş' de yaygın kullanılmakta olan ve farklı üreticilerden alınan tuğla, çimento, kum ve çimento hammaddelerinin ${ }^{226} \mathrm{Ra},{ }^{232} \mathrm{Th}$ ve ${ }^{40} \mathrm{~K}$ aktiviteleri HPGe gama spektroskopisi ile ölçülmüş, bulunan değerlerin standart kabul edilebilir değerlerden yüksek olduğu hesaplanmıştır. Radyolojik indekslerin kabul edilebilir değer aralığında kaldığını not etmişlerdir [10].

- "Natural radioactivity measurement and evaluation of radiological hazards in some commercial flooring materials used in Thiruvannamalai, Tamilnadu, India": Bu makalede, Hindistan Tiruvannamalai, Tamilnadu'da kullanılan zemin kaplama malzemelerinin radyolojik parametreleri NaI gama dedektörü ile ölçülerek elde edilen sonuçlar yayınlanmıştır. Sade fayans, renkli fayans, çini, yeşil siyah ve turuncu granit için elde edilen sonuçlara göre, bu malzemelerin radyasyon risk değerlerinin uluslararası kabul edilen ve Tablo 1'de verilen limit değerlerin altında olmasından dolayı risk oluşturmadığı belirtilmiştir [21].

- "Natural radioactivity and radiation index of the major plutonic bodies in Greece" : Bu çalışmada, Yunanistan'da evlerde dekoratif amaçlarla kullanlan 120 farklı plütonik taş örneği ile granitin doğal radyasyon ölçümleri ve radyolojik indekslerinin hesapları HPGe gama spektroskopisi kullanılarak yapılmıştır. Elde edilen sonuçlara dayanarak plütonik kayaçların dekoratif amaçlar için kullanılabileceğini yayınlamışlardır [22].

- "Assessment of natural radioactivity and radiological hazards in building materials used in Yan'an, China" : Çin'de Yan'an bölgesinde yaygın olarak kullanılan tuğla, çimento, agrega ve kum yapı malzemelerinin doğal radyoaktivite değerlerini ve radyolojik indekslerini $\mathrm{NaI}$ dedektörü kullanarak ölçmüştür. Elde edilen sonuçlara dayanarak bu malzemelerin güvenle kullanılabileceğini yayınlamışlardır [23].

- "Assessment of natural radioactivity levels of cements and cement composites in the Slovak Republic" : Bu araştırmada, Slovakya çimento fabrikalarından alınan 8 farklı çimento örneği ile 5 farklı çimento kompozitinin radyoaktivite değerleri NaI dedektörü ile ölçülerek, radyolojik indeksleri hesaplanmıştır. Çimentoların radyolojik parametre değerleri, kompozitlerin rayolojik parametrelerinden düşük bulunmuştur [24].

- "First characterization of natural radioactivity in building materials manufactured in Albania": Bu makalede, Arnavutluk' ta üretilen kilden yapılmış tuğlaların ve çimento örneklerinin ${ }^{226} \mathrm{Ra},{ }^{232} \mathrm{Th}$ ve ${ }^{40} \mathrm{~K}$ aktivite değerleri ve radyolojik parametreleri HPGe gama spektroskopisi kullanılarak araştırılmıştır. Bu malzemelerin kullanımında herhangi bir radyolojik risk olmadığı bu yayında belirtilmiştir [25].

- "Assessment of radiological hazards of naturally occurring radioactive materials in cement industry" : Bu araştırmada, Pakistan'da üretilmekte olan portland çimentosu, kireçtaşı, kil ve alçıtaşının ${ }^{226} \mathrm{Ra},{ }^{232} \mathrm{Th}$ ve ${ }^{40} \mathrm{~K}$ aktiviteleri HPGe 
gama spektroskopi sistemi kullanılarak bulunmuştur. Bulunan değerler, Tablo 1'de verilen uluslararası limitler ile karşılaştırılmış, sonuçların bu değerler ile uyumlu olduğunu belirtmişlerdir [26].

- "Natural radioactivity levels in building materials used in Egypt" : $\mathrm{Bu}$ çalışmada, Mısır' da yapı duvarlarında, pencerelerde, kapılarda kullanılan kil, tuğla, çimento, alçıtaşı, kum, ağaç, demir, cam ve alçının radyoaktivite ölçümleri HPGe spektroskopisi ile yapılmış ve sadece alçı taşının aktivitesine bağlı radyolojik parametre değerlerinin Tablo 1'de verilen limit değerlerden büyük olduğunu yayınlamışlardır [27].

- "Measurement of activity concentrations of 40K, 226Ra and 232Th for assessment of radiation hazards from soils of the southwestern region of Nigeria": Bu makalede, güneydoğu Nijerya'da bulunan 38 farklı şehirden alınan toprak örneklerinin ${ }^{226} \mathrm{Ra},{ }^{232} \mathrm{Th}$ ve ${ }^{40} \mathrm{~K}$ aktiviteleri HPGe dedektörü kullanilarak ölçülmüş ve bu aktivitelere bağlı radyolojik indeksleri hesaplanarak uluslararası değerlerle karşılaştırma yapılmıştır. ${ }^{226} \mathrm{Ra}$ ve ${ }^{232} \mathrm{Th}$ aktiviteleri ortalama değerlerden yüksek bulunmuş ancak radyolojik indekslerin Tablo 1'de verilen uluslararası kabul edilen limitler içinde olduğunu belirtmişlerdir [28].

- "Radionuclide content of local and imported cements used in Egypt" : Bu makalede, 2000 ve 2003 yılları arasında Mısır'da üretilen 29 çimento örneği ve ithal edilen 8 çimento örneğinin aktivite değerleri ve radyum eşdeğer aktivitesi HPGe dedektörü kullanılarak ölçülmüştür. Bütün örneklerde bulunan radyum eşdeğer aktivitesi önerilen sınır seviye olan 370 Bq. $\mathrm{kg}^{-1}$ ' dan düşük bulunmuştur [29].

- "Natural radioactivity in Algerian building materials": Bu çalışmada Cezayir' de yapı malzemesi olarak üretilen ve doğal olarak bulunan, 12 Çimento, 6 çatı asbesti, 12 kırmızı tuğla, 10 seramik, 8 mermer, 9 çakıl taşı, 8 kil tuğla, 12 kum ve 8 kireç/kireç taşı örneğinin radyoaktivitesi HPGe spektroskopi sistemi ile ölçülmüş,

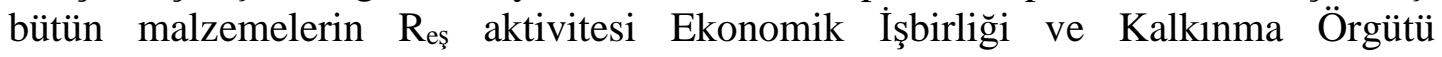
(Organisation for Economic Co-operation and Development (OECD)) tarafından belirlenen limitlerden düşük çıkmıştır [30].

- "Natural radioactivity of building materials used in Austria" : Bu makalede, Avusturya'da kullanılan granit, çakıl, kum, mermer, alçıtaşı gibi doğal ve tuğla, fayans ve kimyasal alçıtaşı gibi imal edilmiş yapı malzemelerinin radyoaktivite ölçümleri yapılmış granit ve bazı tuğla örneklerinin aktivitelerine bağlı radyolojik parametre değerlerinin yüksek olduğunu, diğer malzemelerin radyolojik parametre değerlerinin Tablo 1'de verilen limit değerlerin altında kaldığı belirtmiştir [31].

- "Assessment of natural radioactivity and associated radiation hazards in some Cameroonian building materials" : Bu makalede, Kamerun' da kullanılan, kum, portland çimentosu, çakıl, fayans, kırmızı tuğla, mermer ve siyah kil malzemelerinin radyoaktivite ölçümleri HPGe spektroskopi sistemi kullanılarak elde edilen aktivite sonuçları yayınlanmıştır [32].

\subsection{Türkiye'de yapılmış çalışmalar ve sonuçları}

- "Evaluation of potential exposure risks of natural radioactivity levels emitted from building materials used in Adana, Turkey" : Bu makalede; Adana ilinde kullanılmakta olan 14 farklı yapı malzemesine ait 114 örneğin ${ }^{226} \mathrm{Ra},{ }^{232} \mathrm{Th}$ ve ${ }^{40} \mathrm{~K}$ aktivite değerleri ve radyolojik parametreleri HPGe gama spektroskopi sistemi kullanılarak araştırılmıştır. Bulunan bütün parametre değerleri Tablo 1'de verilen kabul edilebilir limit değerlerin altında olduğu ve bu malzemelerin yapılarda kullanımında sakınca bulunmadığı yayınlanmıştır [16].

- "The investigation natural radioactivity levels in building materials used in 
Gaziantep region" : Bu tez çalışmasında; Gaziantep ilinde yapı inşasında kullanılan 4 farklı kum, 3 farklı çimento, kireç, alçıtaşı, gazbeton, tuğla, 3 farklı mermer ve 2 farklı granit numunesinin aktivite değerleri $\mathrm{NaI}(\mathrm{Tl})$ dedektörü kullanılarak ölçülmüsstür. Granit örneklerininin aktivite değerleri limit değerlerden yüksek bulumuş, diğer örneklerin aktiviteleri ise limit değerin altında belirlenmiştir [12].

- "Assessments of natural radioactivity and radiological hazards in construction materials used in Elazig, Turkey" : Bu araştırmada, Elazı ̆̆ ilinde üretilen kumtaşı, tuğla, alçıtaşı, gazbeton, kireçtaşı, çimento ve mermer örneklerinin ${ }^{238} \mathrm{U},{ }^{232} \mathrm{Th}$ ve ${ }^{40} \mathrm{~K}$ aktiviteleri ve radyolojik parametreleri $\mathrm{NaI}(\mathrm{Tl})$ gama spektroskopisi kullanılarak araştırılmıştır. ${ }^{238} \mathrm{U}$ ve ${ }^{232} \mathrm{Th}$ için elde edilen sonuçların her iki izotop için dünya ortaması olan $40 \mathrm{~Bq} \cdot \mathrm{kg}^{-1}$ [8], ile aynı olduğu, bütün örnekler için hesaplanan radyum eşdeğer parametresinin $1.5 \mathrm{mSv} / \mathrm{y}$ den az olduğunu, iki numunede alfa ve gama indeks değerlerinin limit değerin üzerinde olduğunu belirtmişlerdir [33].

- "Natural radioactivity and radiation hazards in some building materials used in Isparta, Turkey" : Bu çalışmada, Isparta ilinde kullanılmakta olan kil, tuğla, çimento, kireçtaşı, gazbeton, limra, alçıtaşı, seramik ve çakılların ${ }^{226} \mathrm{Ra},{ }^{232} \mathrm{Th}$ ve ${ }^{40} \mathrm{~K}$ aktivite ölçümleri ve radyolojik parametre hesapları $\mathrm{NaI}(\mathrm{Tl})$ gama spektroskopi sistemi ile yapılmıştır. Bütün örnekler için elde edilen sonuçların uluslararası önerilen ve Tablo 1'de verilen limit değerleri aşmadığı belirtilmiştir [34].

- "Measurement of the natural radioactivity in building materials used in Ankara and assessment of external doses": Bu makalede Ankara ilinde inșa alanlarından alınan 20 farklı yapı malzemesine ait toplam 183 örneğin ${ }^{226} \mathrm{Ra},{ }^{232} \mathrm{Th}$ ve ${ }^{40} \mathrm{~K}$ aktivite ölçümleri HPGe dedektörü kullanılarak yapılmıştır. 4 malzemenin yıllık doz kriteri olan $0.3 \mathrm{mSv} / \mathrm{y}^{\prime}$ i 5 malzemenin yıllık doz limiti olan $1 \mathrm{mSv} / \mathrm{y}$ 'i sağladığını, sadece 1 malzemenin bu limiti aştığını yayınlamışlardır [35].

- "Natural radionuclides in the building materials used in Manisa city, Turkey" : Bu araştırmada Manisa ilinde kullanılan tuğla, kum, çimento ve çakıl malzemelerinin ${ }^{238} \mathrm{U},{ }^{232} \mathrm{Th}$ ve ${ }^{40} \mathrm{~K}$ aktivite ölçümleri $\mathrm{NaI}(\mathrm{Tl})$ gama spektroskopi sistemi ile yapılarak bulunan aktivitelere bağlı radyum eşdeğer aktivitesini hesaplanmışdır. En yüksek $\mathrm{Ra}_{\mathrm{e}}$ değeri kum ve çakıl örneklerinde bulunduğunu belirtmişlerdir [36].

- “Assesment of environmental radioactivity for Batman, Turkey": Bu makalede; Batman ilinde yapı malzemesi olarak kullanılan çimento, kum, kırmızı tuğla, beyaz tuğla, alçıtaşı, alçı ve mermerin radyolojik ölçümleri HPGe gama spektroskopisi ile yapılarak elde edilen sonuçlar diğer iller için yapılan çalışmalar ve Tablo 1'de verilen uluslararası kabul edilen limit değerler ile karşılaştırılmış, ölçümü yapılan numunelerin radyolojik risk taşımadıkları belirtilmiştir. [37].

- "Natural radioactivity and hazard-level assessment of Portland cements in Turkey"[2017]: Bu makalede, Türkiye' nin her bölgesindeki çimento fabrikasından alınan 16 farklı portland çimento numunesinin ${ }^{226} \mathrm{Ra},{ }^{232} \mathrm{Th}$ ve ${ }^{40} \mathrm{~K}$ aktivite ölçümleri HPGe spektrokopisi ile yapılmış, bulunan aktivitelere bağlı radyolojik parametre değerleri hesaplanarak elde edilen sonuçlar farklı ülkelerde aynı alanda yapılan çalışmalar ile karşılaştırılmıştır. Araştırma sonuçlarına göre, numunelerin aktivite ve parametre değerlerinin diğer ülkelerdeki çalışmalardan ve Tablo 1'de belirtilen standart limitlerden az olduğu yayınlanmıştır [38].

- "Natural radioactivity $\left({ }^{226} \mathrm{Ra},{ }^{232} \mathrm{Th}\right.$ and $\left.{ }^{40} \mathrm{~K}\right)$ and assessment of radiological hazards in the Kestanbol granitoid, Turkey" : Bu araştırmada, Ezine bölgesindeki 10 farklı granit numunesinin doğal radyoaktivite ve radyolojik risk indeksleri HPGe gama spektroskopisi kullanılarak araştırılmıştır. Elde edilen sonuçlar bölgedeki granitlerin aktivite değerlerinin ve buna bağlı olarak soğrulan doz oranın yüksek olduğunu göstermiştir [39]. 
- "Assesment of natural radioactivity in cements used as building materials in Turkey" : Bu çalışmada, Türkiye' de kullanılan 42 farklı çimento örneğinin ${ }^{226} \mathrm{Ra}$, ${ }^{232} \mathrm{Th}$ ve ${ }^{40} \mathrm{~K}$ aktivte ölçümleri ve radyolojik parametre değerleri $\mathrm{NaI}(\mathrm{Tl})$ gama spektroskopi sistemi ile ölçülerek farklı ülkelerde yapılan çalışmalar, Avrupa Komisyonunca (European Commision, EC) ve Birleşmiş Milletler Atom Radyasyonu Etkileri Bilimsel Komitesi (United Nations Scientific Committee on the Effects of Atomic Radiation (UNSCEAR)) tarafından belirlenen standartlar ile karşılaştırılmıştır. Analizler sonucu bulunan ortalama aktivite değerleri ${ }^{226} \mathrm{Ra},{ }^{232} \mathrm{Th}$, ${ }^{40} \mathrm{~K}$ için sirası ile $34 \pm 4 \mathrm{~Bq} \cdot \mathrm{kg}^{-1}, 15 \pm 2 \mathrm{~Bq} \cdot \mathrm{kg}^{-1}, 220 \pm 13 \mathrm{~Bq} \cdot \mathrm{kg}^{-1}$ olarak yayınlanmıştır. Araştırma sonuçları bir çimento örneği dışında diğer örneklerin aktivite ve parametre değerlerinin limit değerler ile uygun olduğunu göstermiş̦tir. 35 numaralı örnekteki yüksek aktivtenin katkı malzemesi olarak kullanılan yüksek fırın cüruflu külden kaynaklandığı açıklanmıştır [40].

- ${ }^{6226} \mathrm{Ra},{ }^{232} \mathrm{Th}$ and ${ }^{40} \mathrm{~K}$ Activity concentrations and radiological hazards of building materials in Muğla, Turkey" : Bu araştırmada; Muğla ilinde yapı malzemesi olarak kullanılan 5 farklı mermer, 3 farklı tuğla ve iki farklı çimento örneğinin aktivite değerleri HPGe dedektörü kullanılarak ölçülmüş, bulunan aktivitelere bağlı risk indeksleri hesaplanarak uluslararası limit değerler ile karşılaştırılmıştır. Elde edilen sonuçların önerilen limit değerlerin altında olduğu ve bu malzemelerin kullanımında sakınca olmadığını yayınlanmıştır [41].

- "Radiological significance of cement used in building construction in Turkey" : $\mathrm{Bu}$ araştırmada; farklı çimento fabrikalarından alınan 7 farklı çimentoya ait 141 örneğin ${ }^{226} \mathrm{Ra},{ }^{232} \mathrm{Th}$ ve ${ }^{40} \mathrm{~K}$ aktivite değerleri ve radyolojik parametreleri HPGe gama spektroskopisi kullanılarak ölçülmüştür. Analizler sonucu bulunan ortalama aktivite değerleri ${ }^{226} \mathrm{Ra},{ }^{232} \mathrm{Th},{ }^{40} \mathrm{~K}$ için sırası ile $40.0 \pm 27.1,28.0 \pm 20.9$ and $248.3 \pm 95.0$ Bq. $\mathrm{kg}^{-1}$ olarak yayınlanmıştır. Elde edilen sonuçlar, bu çimentoların kullanımında radyolojik açıdan ciddi bir risk bulunmadığını göstermiştir [42].

- "Natural radioactivity measurements in building materials used in Samsun, Turkey" : Bu çalışmada, 11 yaygın kullanılan yapı malzemesine ait 35 farklı örneğin aktivite ve parametre değerleri HPGe dedektörü kullanılarak ölçülmüş, elde edilen sonuçlar uluslararası limit değerler ile karşılaştırılmıştır. Çalışma sonucunda, bu malzemelerin insan sağlığı açısından radyolojik risk taşımadıkları belirtilmiştir [43].

- "Assessment of natural radiation exposure levels and mass attenuation coefficients of lime and gypsum samples used in Turkey" : Bu makalede; Türkiyenin 7 farklı bölgesindeki üreticilerden, yapı malzemesi satıcılarından ve inşaat alanlarından alınan 87 farklı kireç ile 59 farklı alçıtaşı numunesinin aktivite değerleri HPGe gama spektroskopi sistemi ile ölçülmüş, elde edilen aktivitelere bağlı risk indeksleri hesaplanarak, uluslararası önerilen limit değerler ile karşılaştırılmıştır. Kireçtaşı için bulunan ortalama aktivite değerleri ${ }^{226} \mathrm{Ra},{ }^{232} \mathrm{Th},{ }^{40} \mathrm{~K}$ için sırası ile $38 \pm$ $16,20 \pm 9$, and $156 \pm 54 \mathrm{~Bq} \cdot \mathrm{kg}^{-1}$, alçı numuneleri için bulunan ortalama aktivite değerleri ise $17 \pm 6,13 \pm 5$, and $429 \pm 24 \mathrm{~Bq} \cdot \mathrm{kg}^{-1}$ olarak yayınlanmıştır. Araştırma sonucunda hesaplanan aktivite ve risk indeks değerlerinin uluslararası limit değerinden küçük olduğu belirtilmiştir. [44].

- "Natural radionuclide content and radiological hazard associated with usage of quartzite sand samples from Ovacik-Silifke-Mersin open pit as building material in Turkey": Bu makalede; Mersin ilinde ve Ovacik-Silifke de bulunan 15 farklı açık kum ocağından alınan kuvarsit kumların aktivite ve radyolojik parametreleri HPGe gama spektroskopi sistemi ile ölçülmüştür. Kuvarsit kum numuneleri için bulunan ortalama aktivite değerleri ${ }^{226} \mathrm{Ra},{ }^{232} \mathrm{Th},{ }^{40} \mathrm{~K}$ için sırası ile 
$77.5+24.3,6.3+2.8,140.0+124.1$ Bq.kg ${ }^{-1}$ olarak yayınlanmıştır. Aktivitelere bağlı olarak elde edilen risk indekslerinin uluslararası limit değerlerinin altında olduğunu belirtmişlerdir [45].

- "Assessment of the radiological impacts of utilizing coal combustion fly ash as main constituent in the production of cement" : Bu makalede; Bursa Orhaneli termik santralinde linyit yanması sonucu açığa çıkan tozlaştırılmış külün ve bu külün $\% 15, \% 20$ ve $\% 25$ oranlarında katkı olarak kullanılanılmasıla üretilen portland çimentosunun aktivite ve radyolojik parametre ölçümleri HPGe dedektörü ile yapılmıştır. Bütün katkı oranları için elde edilen aktivite ve radyolojik parametre değerlerinin tavsiye edilen limit değerden küçük olduğunu belirtilmişdir [46].

- "Radiation dose estimation and mass attenuation coefficients of cement samples used in Turkey" : Bu araştırmada 6 farklı yapıdaki çimento numunesnin (Portland çimentosu, Portland kompozit çimentosu, puzolan çimentosu, kompozit çimento, sülfat dirençli çimento ve beyaz çimento) aktivite ve radyolojik parametreleri HPGe gama spektroskopi sistemi kullanılarak ölçülmüştür. Çimentolara ait 69 numune Türkiyenin 7 farklı bölgesindeki çimento ve ögütme fabrikalarından alınmıştır. Marmara bölgesi için bulunan ortalama aktivite değerleri ${ }^{226} \mathrm{Ra},{ }^{232} \mathrm{Th},{ }^{40} \mathrm{~K}$ için sırası ile $51 \pm 16,37 \pm 15,296 \pm 110 \mathrm{~Bq} \cdot \mathrm{kg}^{-1}$, Ege bölgesi için, $68 \pm 23,51 \pm 29,353 \pm$ $160 \mathrm{~Bq} \cdot \mathrm{kg}^{-1}$, Akdeniz bölgesi için, $71 \pm 24,56 \pm 27,327 \pm 130 \mathrm{~Bq} / \mathrm{kg}^{-1}$, Karadeniz bölgesi için, $44 \pm 20,163 \pm 6,361 \pm 160 \mathrm{~B} / \mathrm{kg}$, İçanadolu bölgesi için, $25 \pm 1$, $34 \pm 7$, $324 \pm 60 \mathrm{~Bq} \cdot \mathrm{kg}^{-1}$, Doğu Anadolu bölgesi için, $38 \pm 11,25 \pm 7,253 \pm 52 \mathrm{~Bq} \cdot \mathrm{kg}^{-1}$, Güneydoğu Anadolu bölgesi için, $11 \pm 1,25 \pm 12,312 \pm 140$ Bq.kg ${ }^{-1}$ olarak bulunmuştur. Elde edilen sonuçlar diğer çalışmalardan elde edilen sonuçlar ve tavsiye edilen standart limitlerle karşılaştırılmış, bulunan sonuçlar ile farklılık gözlenmediği belirtilmiştir [47].

- "Radiological impacts of the usability of clay and kaolin as raw material in manufacturing of structural building materials in Turkey" : Bu makalede, seramik, tuğla ve çimento endüstrisinde yaygın olarak kullanılan ve farklı taş ocaklarından alınan 50 farklı kil ve kaolin numunesinde bulunan ${ }^{226} \mathrm{Ra},{ }^{232} \mathrm{Th}$ ve ${ }^{40} \mathrm{~K}$ 'nın aktivite ölçümleri ve radyojik risk faktörleri HPGe gama spektroskopisi kullanılarak incelenmiştir. Kil numuneleri için bulunan ortalama aktivite değerleri ${ }^{226} \mathrm{Ra},{ }^{232} \mathrm{Th},{ }^{40} \mathrm{~K}$ için sırası ile $39.3 \pm 22.7,49.6 \pm 27.9,569.5 \pm 181.0 \mathrm{~Bq} \cdot \mathrm{kg}^{-1}$ kaolin örnekleri için bulunan ortalama aktivite değerleri ise $82.0 \pm 37,94.8 \pm 49.2$, $463.6 \pm 544.9$ Bq. kg ${ }^{-1}$ olarak bildirilmiştir. Kil için hesaplanan gama indeksinin limit değerden biraz fazla olduğu, diğer parametrelerin tavsiye edilen limit değerin altında olduğunu yayınlanmıştır [48].

- “Assesment of natural radioactivity of sand used in Turkey" : Bu çalışmada, Türkiye'de inşa malzemesi olarak kullanılan kum örneklerinin radyoaktivite ve radyolojik parametre değerleri araştırılmış ve elde edilen sonuçlara göre bu değerlerin limit değerlerin altında olduğu belirtilmiştir [49].

- "Natural radioactivity and dose rates in commercially used marble from Afyonkarahisar - Turkey" : Bu araştırmada, Afyonkarahisar bölgesinde üretilen 5 farklı mermer örneğinin radyoaktivite ve radyolojik risk parametrelerinin ölçümleri yapılmıştır. Elde edilen sonuçlar, 3 mermer örneği için soğrulan doz oranının yüksek bulunduğunu fakat mermerlerin aktivite değerlerinin kabul edilebilir limitler içinde olduğunu göstermiştir [50].

- "Environmental radioactivity measurements in Kastamonu region of northern Turkey" : Bu makalede, Kastamonu ilindeki binalarda bulunan Radon $\left({ }^{222} \mathrm{Rn}\right)$ aktivitesi ve toprak ve su örneklerinin ${ }^{226} \mathrm{Ra},{ }^{232} \mathrm{Th},{ }^{40} \mathrm{~K}$ aktivite değerleri araştırılarak diğer illerde yapılan çalışmalar ile karşılaştırılmıştır. Elde edilen aktivite sonuçlarının 
diğer iller ile aynı seviyede olduğu belirtilmiştir [51].

- "Indoor ${ }^{222} \mathbf{R n}$ concentrations in İstanbul Houses" : Bu makalede, İstanbul'daki 400 evde bulunan ortalama ${ }^{222} \mathrm{Rn}$ aktiviteleri ölçülmüştür. ${ }^{222} \mathrm{Rn}$ aktivitesinin 10 $\mathrm{Bq} / \mathrm{m}^{3}$ ile $260 \mathrm{~Bq} / \mathrm{m}^{3}$ arasında olduğu, ortalama ${ }^{222} \mathrm{Rn}$ aktivitesinin 50 Bq. ${ }^{-3}$ olarak hesaplandığı yayınlanmıştır. [52].

- "Indoor radon concentration in Adana, Turkey": Bu makalede, Adana' da bulunan evlerin kış ve yaz aylarındaki ${ }^{222} \mathrm{Rn}$ aktivite değerleri ölçülerek mevsimsel değişimin radon konsantrasyonundaki etkilerine bakılmıştır. Mevsimsel değişimin sıcaklık nedeniyle radon konsantrasyonunu etkilediği ancak elde edilen sonuçların limit değerlerin altında kaldığını yayınlanmıştır [53].

\section{Değerlendirme ve sonuç}

$\mathrm{Bu}$ çalışmada Türkiye'de ve diğer ülkelerde yapı malzemesi olarak kullanılan malzemelerin radyoaktivite ve radyolojik parametre ölçümleri konusunda yapılmış farklı çalışmalar derlenerek okuyucuların dikkatine sunulmuştur. Tablo 2'de malzeme çeşitleri, araştırmanın yapıldığı ülke ve araştırmayı yapan yayına ait referanslar verilmiş, Tablo 3'de, bu çalışmalardan elde edilen araştırma sonuçları karşılaştırma amaciyla sunulmuştur.

Tablo 2. Yapı malzemelerinden yayılan radyasyonun aktivite ölçümleri ile ilgili yapılan çalışmalar.

\begin{tabular}{|c|c|c|}
\hline Malzeme & Ülke & Referans \\
\hline Çimento & $\begin{array}{l}\text { Türkiye, Pakistan, Mısır, Slovakya, Çin } \\
\text { Arnavutluk, Bangladeş, Cezayir, } \\
\text { Kamerun }\end{array}$ & $\begin{array}{l}{[10,12,16,23-26,29,30,33-39,} \\
41-44,47,49]\end{array}$ \\
\hline Tuğla & $\begin{array}{l}\text { Türkiye, Avusturya, Mısır, Arnavutluk } \\
\text { Cezayir, Çin, Bangladeş }\end{array}$ & $\begin{array}{l}{[10,12,16,23,24,26,27,30,31 \text {, }} \\
33-38,42,44]\end{array}$ \\
\hline Kum & $\begin{array}{l}\text { Türkiye, Avusturya, Mısır, Cezayir, } \\
\text { Çin } \\
\text { Bangladeș }\end{array}$ & $\begin{array}{l}{[10,12,16,23,27,30,31,33,34,} \\
36-38,44,46]\end{array}$ \\
\hline Mermer ve Granit & $\begin{array}{l}\text { Türkiye, Avusturya, Hindistan, Bosna } \\
\text { Hersek, Yunanistan, Cezayir }\end{array}$ & $\begin{array}{l}{[16,18,21,22,30,31,33,34,36,} \\
38,40,42,44,50]\end{array}$ \\
\hline Agrega ve çakıl & $\begin{array}{l}\text { Türkiye, İsveç, Çin } \\
\text { Avusturya, Kamerun }\end{array}$ & {$[16,20,23,31,32,35-37,44]$} \\
\hline Çimento ham maddesi & Türkiye, Slovakya, Bangladeş & {$[10,24,47,49]$} \\
\hline $\begin{array}{l}\text { Kireç, Kireç taş1, Alçı, } \\
\text { Alç1 taşı }\end{array}$ & $\begin{array}{l}\text { Türkiye, Avusturya, Mısır, Pakistan, } \\
\text { Cezayir }\end{array}$ & {$[16,26,27,30,31,33-36,38,45]$} \\
\hline${ }^{222} \mathrm{Rn}$ gazi & Türkiye & [51-53] \\
\hline Demir ve cam & Misir & [27] \\
\hline
\end{tabular}

İnsanların yaşamının \%80'lik bölümünü kapalı ortamlarda (ev, ofis, okul) geçirdiği göz önüne alındığında yapı malzemelerinden yayılan radyasyonun uzun vadede insan sağlığı açısından önemli olduğu görülmektedir. $\mathrm{Bu}$ alanda dikkate alınması gereke limit değerler UNSCEAR ve EC komisyonları tarafından belirlenmiş ve araştırma sonuçları değerlendirilirken bu limit değerler kullanılmıştır. Farklı ülkelerde yapılan araştırma sonuçları değerlendirildiğinde pek çok malzeme için aktivite ve radyolojik parametre değerlerinin belirlenen limit değerlerinin altında olduğu bildirilmiştir. Türkiye'de ve Dünya' da inşa edilen yapıların büyük çoğunluğunun beton ve tuğladan oluştuğu göz önüne alındığında, araştırmalarda ağırlığın çimento, tuğla ve kum malzemesine verildiği görülmektedir. Limit değerlerinin üzerinde sonuçlar veren bazı çimento örneklerinde, 
yüksek aktivite kaynağının çimento katkı malzemesi olarak kullanılan kül kaynaklı olduğu ayrıca, limit değerleri aşan yüksek aktivite değerlerinin granit ve mermer örnekleri için hesaplandığı görülmüştür.

Tablo 3. Çeşitli yapı malzemesi numuneleri için bulunan araştırma sonuçları.

\begin{tabular}{|c|c|c|c|c|c|}
\hline Numune & Ülke/Şehir & ${ }^{226} \mathrm{Ra}$ (Bq.kg-1) & ${ }^{232} \mathrm{Th}\left(\mathrm{Bq} \cdot \mathrm{kg}^{-1}\right)$ & ${ }^{40} \mathrm{~K}\left(\mathrm{~Bq} \cdot \mathrm{kg}^{-1}\right)$ & Referans \\
\hline \multirow{12}{*}{ Çimento } & Ankara & $39.9 \pm 18.0$ & $26.4 \pm 9.8$ & $316.5 \pm 88.1$ & [35] \\
\hline & Gaziantep & 17.01 & 15.72 & 188.9 & [12] \\
\hline & Batman & $36 \pm 8$ & $27 \pm 10$ & $389 \pm 48$ & [37] \\
\hline & Bangladeş & $60.5 \pm 2.1$ & $64.7 \pm 2.6$ & $952.2 \pm 2.6$ & [10] \\
\hline & Misir & 210.9 & 33.9 & 307.1 & [27] \\
\hline & Slovakya & 19.1 & 26.3 & 489.4 & [24] \\
\hline & Çin & 63.0 & 68.7 & 303.4 & [23] \\
\hline & Arnavutluk & $33.4 \pm 6.4$ & $42.2 \pm 7.6$ & $644.1 \pm 64.2$ & [25] \\
\hline & Pakistan & $34.2 \pm 11.9$ & $29.1 \pm 3.6$ & $295.1 \pm 66.9$ & [13] \\
\hline & Cezayir & $41 \pm 7$ & $27 \pm 3$ & $422 \pm 3$ & [30] \\
\hline & Kamerun & $27 \pm 4$ & $15 \pm 1$ & $277 \pm 117$ & [32] \\
\hline & İsveç & 16 & 16 & 320 & [20] \\
\hline \multirow{9}{*}{ Tuğla } & Ankara & $31.2 \pm 7.6$ & $37.2 \pm 7.8$ & $775.8 \pm 149.6$ & [35] \\
\hline & Gaziantep & 81.84 & 18.96 & 268.11 & [12] \\
\hline & Batman & $21 \pm 5$ & $21 \pm 5$ & $398 \pm 14$ & [37] \\
\hline & Misır & 77.5 & 81.7 & 398.4 & [27] \\
\hline & Arnavutluk & $55.0 \pm 5.8$ & $17.0 \pm 3.3$ & $179.7 \pm 48.9$ & [25] \\
\hline & Cezayir & $65 \pm 7$ & $51 \pm 5$ & $675 \pm 4$ & [30] \\
\hline & Çin & 47.3 & 61.6 & 821.8 & [23] \\
\hline & Bangladeş & $57.5 \pm 2.2$ & $75.8 \pm 2.9$ & $1080 \pm 12.7$ & [10] \\
\hline & Kamerun & $38 \pm 4$ & $81 \pm 2$ & -- & [32] \\
\hline \multirow{9}{*}{ Kum } & Ankara & $22.9 \pm 12.9$ & $26.4 \pm 16.2$ & $527.2 \pm 129.2$ & [35] \\
\hline & Gaziantep & 9,52 & -- & 198,85 & [12] \\
\hline & Batman & $32 \pm 4$ & $22 \pm 5$ & $543 \pm 19$ & [37] \\
\hline & Misır & 23.2 & 11.3 & 141.8 & {$[27]$} \\
\hline & Cezayir & $12 \pm 1$ & $7 \pm 1$ & $74 \pm 7$ & [30] \\
\hline & Çin & 13.1 & 19.0 & 851.7 & [23] \\
\hline & Bangladeş & $49.4 \pm 3.0$ & $71.6 \pm 3.5$ & $927.2 \pm 13.8$ & [10] \\
\hline & Kamerun & $14 \pm 1$ & $31 \pm 1$ & $586 \pm 13$ & [32] \\
\hline & İsveç & 22 & 18 & 880 & [20] \\
\hline \multirow{9}{*}{$\begin{array}{l}\text { Mermer veya } \\
\text { Granit }\end{array}$} & Ankara & $67.5 \pm 47.6$ & $77.4 \pm 53.0$ & $915.3 \pm 361.2$ & [35] \\
\hline & Batman & $18 \pm 7$ & $8 \pm 4$ & $68 \pm 16$ & [37] \\
\hline & Gaziantep & 64.83 & 50.88 & 871.29 & [12] \\
\hline & Çanakkale & $94-637$ & $120-601$ & $1074-1527$ & [39] \\
\hline & Hindistan & $6.1-14.2$ & $4.6-61.6$ & $139.1-1366.8$ & [21] \\
\hline & Bosna Hersek & $129 \pm 47$ & $92 \pm 33$ & $1045 \pm 138$ & [18] \\
\hline & Yunanistan & $74 \pm 5$ & $85 \pm 5$ & $881 \pm 30$ & [22] \\
\hline & Cezayir & $23 \pm 2$ & $18 \pm 2$ & $310 \pm 3$ & {$[30]$} \\
\hline & İsveç & 97 & 195 & 1155 & [20] \\
\hline \multirow{5}{*}{$\begin{array}{l}\text { Agrega ve } \\
\text { Çakı1l }\end{array}$} & Ankara & $21.6 \pm 4.2$ & $25.8 \pm 6.5$ & $482.2 \pm 51.8$ & [35] \\
\hline & Gaziantep & -- & -- & -- & [12] \\
\hline & Çin & 37.2 & 48.5 & 678.0 & [23] \\
\hline & Cezayir & $24 \pm 3$ & $10 \pm 1$ & $259 \pm 2$ & [30] \\
\hline & Kamerun & $24 \pm 3$ & $139 \pm 13$ & $1161 \pm 108$ & [32] \\
\hline \multirow{3}{*}{$\begin{array}{l}\text { Çimento ham } \\
\text { maddesi (kül) }\end{array}$} & Türkiye & $366.6 \pm 100.1$ & $113.7 \pm 43.0$ & $460.2 \pm 119.3$ & [46] \\
\hline & Slovakya & 10.8 & 20.5 & 494.4 & [24] \\
\hline & Bangladeş & $117.8 \pm 6.2$ & $157.3 \pm 8.6$ & $1463.3 \pm 22.8$ & [10] \\
\hline \multirow{7}{*}{$\begin{array}{c}\text { Kireç taşı } \\
\text { veya alçı taşı }\end{array}$} & Ankara & $11.9 \pm 9.5$ & $5.4 \pm 2.2$ & $52.7 \pm 41.2$ & [35] \\
\hline & Batman & $48 \pm 4$ & $22 \pm 9$ & $169 \pm 28$ & [37] \\
\hline & Gaziantep & 58.16 & -- & 94.94 & [12] \\
\hline & Misir & 659.7 & 162.1 & 145.1 & [27] \\
\hline & Pakistan & $41.2 \pm 6.7$ & $39.3 \pm 6.9$ & $195.1 \pm 29.2$ & [13] \\
\hline & Cezayir & $16 \pm 3$ & $13 \pm 2$ & $36 \pm 3$ & [30] \\
\hline & Kamerun & $5 \pm 1$ & $1.02 \pm 0.25$ & $106 \pm 5$ & [32] \\
\hline
\end{tabular}


Derlenen çalışmaların geneli; çimento, kum ve tuğla üzerine yapılmış olup cam, ağaç ve demir gibi yapı malzemelerin radyoaktivite ölçümlerinin sadece bir çalışmada yayınladığı görülmüştür [27]. Cam ve demirin yapılarda kullanılan önemli yap1 malzemeleri olduğu ve bu malzemelerin doğal hammaddelerden üretildiği göz önüne alındığında, demir ve camın aktivite ve radyolojik parametre ölçümleri insan sağlığı açısından önemli ve gereklidir. Yapı malzemelerinde ${ }^{238} \mathrm{U}$ bozunma zincirinde açığa çıkan önemli bir radyoaktif kaynak da ${ }^{222} \mathrm{Rn}$ gazıdır. Bu gazın solunum sistemine girmesiyle uzun vadede akciğer kanseri gibi önemli rahatsızlıklar açığa çıkabilmektedir. $\mathrm{Bu}$ nedenle Türkiye'de bazı şehirlerdeki binalarda radon gazının ölçümleri ayrıca yapılmış ve sonuçları yayınlanmıştır[51-53].

Yapılan çalışmalar incelendiğinde, Türkiye'de ve diğer ülkelerde yapı malzemesi radyoaktivitesi konusunda çok sayıda çalışma yapıldığı ve bu konunun insan sağlığı açısından çok önemli olduğu anlaşılabilir. Malzemelerin dikkatli seçimi ve düşük radyoaktiviteye sahip malzemelerin yapılarda kullanımı, kanser ve akciğer rahatsızlıkları gibi önemli hastalıkların azalmasında katkı sağlayacaktır[3-5]. Tablo 3'de verilen değerler örnek amaçlı olarak sunulmuştur.

\section{Kaynaklar}

[1] Dihn, N.C., Dulinski, M., Jodlowski, P., Nowak, J., Rozanski, K. ve Sleziak, M., Natural radioactivity in groundwater - a review, Isotopes Environmental Health Studies, 47, 4, 415 - 437, (2011).

[2] UNSCEAR (United Nations Scientific Committee on the Effects of Atomic Radiation), Sources, Effects and Risks of Ionizing Radiation, New York, (1988).

[3] Isam, S., Sara, A., Sahar, E. ve Hajo, I., Radiation exposure of workers in storage areas for building materials, Journal of Taibah University for Science, 8, 394400, (2014).

[4] Kendall, G.M. ve Smith, T.J., Doses to organs and tissues from radonand its decay products, Journal of Radiological Protection, 22, 4, 389-406, (2002).

[5] Duran, T.M., Barros-Dios, M.J., Villar, A.F. ve Ravina A.R., Residential radon and lung cancer in never smokers. Asystematic review, Cancer Letters, 345, 1, 21-26, (2014).

[6] OECD, "Organization for Economic Cooperation and Development, Exposure to radiation from the natural radioactivity in building materials," Paris, (1979).

[7] UNSCEAR, "Exposure from natural radiation sources. Report to general assembly with annexes (Annex B)," New York: United Nations, (2000).

[8] EC (European Commission), "Radiological protection principles concerning the natural radioactivity of building materials.," Radiation protection 112. Directorate General Environment, Nuclear Safety and Civil Protection, Cenevre, (1999).

[9] Grupen, C. ve Shwartz B., Particle Detectors. New York: Cambridge University Press, (2008).

[10] Asaduzzaman, K., Mannan, F., Khandaker, M., Farook, M.S. ve Elkezza, A., Assessment of Natural Radioactivity Levels and Potential Radiological Risks of Common Building Materials Used in Bangladeshi Dwellings, Public Library of Science (PLoS one), 16, 10, 10, (2015).

[11] Khandaker, M.U., Jojo, P.J., Kassim, H.A. ve Amin, Y.M., Radiometric analysis of construction materials using HPGe gamma-ray spectrometry, Radiation 
Protection Dosimetry, 152, 1, 33-37, (2012).

[12] Zuhur, S.The investigation natural radioactivity levels in building materials used in Gaziantep region, M. Sc. Thesis Gaziantep Üniversitesi Fen Bilimleri Enstitüsü (2014).

[13] Rahman, S.U., Rafique, M. ve Jabbar, A., Radiological hazards due to naturally occurring radionuclides in the selected building materials used for the construction of dwellings in four districts of the Punjab province, Pakistan, Radiation Protection Dosimetry, 153, 3, 352-360, (2013).

[14] Arabi, A.M., Ahmed, N.K. ve Salahel Din, K., Assessment of terrestrial gamma radiation doses for some Egyptian granite samples, Radiation Protection Dosimetry, 128, 3, 382-385, (2008).

[15] Gupta, M. ve Chauhan, R.P., Estimation of Low-Level Radiation Dose from Some Building Materials Using Gamma Spectroscopy, Indoor and Built Environment, 21, 3, 465-473, (2012).

[16] Solak, S., Turhan, Ş., Ugur, F.A., Goren, E., Gezer, F., Yeğingil, Z. ve Yeğingil, İ., Evaluation of potential exposure risks of natural radioactivity levels emitted from building materials used in Adana, Turkey, Indoor and Built Environment, 23, 4, 594-602, (2014).

[17] Mathew, P.J. ve Beretka, J., Natural radioactivity of Australian building materials, industrial waste and by-products, Health Physics, 48, 87-95, (1985).

[18] Todorović, N., Hansman, J., Mrđa, D., Nikolov, J., Kardos, R. ve Krmar, M., Concentrations of $226 \mathrm{Ra}, 232 \mathrm{Th}$ and $40 \mathrm{~K}$ in industrial kaolinized granite, Journal of Environmental Radioactivity, 168, 10-14, (2017).

[19] Morsi, T., Hegazy, R. ve Badawy W., Radiological impact assessment to the environment due to waste from disposal of porcelain, International Journal of Radiation Biology, 93, 6, 653-659, (2017).

[20] Silfwerbrand, J., Jelinek, C., Trägardh, J., Isaksson, M. ve Döse, M., Naturally occurring radioactivity in some Swedish concretes and their constituents Assessment by using I-index and dose-model, Journal of Environmental Radioactivity, 155-156, 105-111, (2016).

[21] Raghub Y., Sivakumarc, S., Chandrasekarand, A., Prem Anande, D., Ravisankar, R. ve Senthilkumara, G., Natural radioactivity measurement and evaluation of radiological hazards in some commercial flooring materials used in Thiruvannamalai, Tamilnadu, India, Journal of Radiation Research and Applied Sciences, 7, 1, 116-122, (2014).

[22] Christofides, G., Koroneos, A., Papadopoulou L., Papastefanou, C., Stoulos, S. ve Papadopoulos, A., Natural radioactivity and radiation index of the major plutonic bodies in Greece, Journal of Environmental Radioactivity, 124, 227238, (2013).

[23] Lu, X., Li, N., Yang, G. ve Zhao, C., Assessment of natural radioactivity and radiological hazards in building materials used in Yan'an, China, Health Physics, 104, 3, 325-331, (2013).

[24] Eštoková, A. ve Palaščáková, L., Assessment of natural radioactivity levels of cements and cement composites in the Slovak Republic, International Journal of Environmental Research and Public Health, 10, 12, 7165-7179, (2013).

[25] Xhixha, G., Ahmeti, A., Bezzon, G.P., Bitri, M., First characterisation of natural radioactivity in building materials manufactured in Albania, Radiation 
Protection Dosimetry, 155, 2, 217-223, (2013).

[26] Aslam, M., Gul, R., Ara, T. ve Hussain, M., Assessment of radiological hazards of naturally occurring radioactive materials in cement industry, Radiation Protection Dosimetry, 151, 3, 483-488, (2012).

[27] Ahmad, F., Natural radioactivity levels in building materials used in Egypt, Radiation Effects and Defects in Solids, 162, 43-52, (2011).

[28] Ajayi, O., Measurement of activity concentrations of 40K, 226Ra and 232Th for assessment of radiation hazards from soils of the southwestern region of Nigeria, Radiation and Environmental Biophysics, 48, 3, 323-332, (2009).

[29] Mahmoud, K.R., Radionuclide content of local and imported cements used in Egypt, Journal of Radiological Protection, 27, 1, 69 - 77, (2007).

[30] Amrani, D. ve Tahtat, M., Natural radioactivity in Algerian building materials, Applied Radiation and Isotopes, 54, 4, 687-689, (2001).

[31] Sorantin, H. ve Steger, F., Natural Radioactivity of Building Materials in Austria, Radiation Protection Dosimetry, 7, 1-4, 59-61, (1984).

[32] Ngachin, M., Garavaglia, M., Giovani, C., Kwato Njock, M.G. ve Nourreddine, A., Assessment of natural radioactivity and associated radiation hazards in some Cameroonian building materials, Radiation Measurements, 42, 1, 61-67, (2007).

[33] Baykara, O., Karatepe, Ş. ve Doğru, M., Assessments of natural radioactivity and radiological hazards in construction materials used in Elazig, Turkey, Radiation Measurement, 46, 153-158, (2011).

[34] Mavi, B. ve Akkurt, I., Natural radioactivity and radiation hazards in some building materials used in Isparta, Turkey, Radiation Physics and Chemistry, 79, 9, 933-937, (2010).

[35] Turhan, S., Baykan, U.N. ve Sen, K., Measurement of the natural radioactivity in building materials used in Ankara and assessment of external doses, Journal of Radiological Protection, 28, 1, 83-91, (2008).

[36] Erees, F.S., Dayanıklı, S.A. ve Çam, S., Natural Radionuclides in the Building Materials used in Manisa City, Turkey, Indoor and Built Environment, 15, 5, 495-498, (2006).

[37] Damla, N., Çevik, U., Kobya, A.İ. ve Ataksor B., Assessment of environmental radioactivity for Batman, Turkey, Environmental Monitoring and Assessment, 160, 401-412, (2010).

[38] Altun, M., Sezgin, N., Nemlioğlu, S., Karakelle, B., Can, N. ve Temelli U.E., Natural radioactivity and hazard-level assessment of Portland cements in Turkey, Journal of Radioanalytical and Nuclear Chemistry, 314, 2, 941-948, (2017).

[39] Canbaz, B., Çam, N.F., Yaprak, G. ve Candan, O., Natural radioactivity (226Ra, $232 \mathrm{Th}$ and $40 \mathrm{~K}$ ) and assessment of radiological hazards in the Kestanbol granitoid, Turkey, Radiation Protection Dosimetry, 141, 2, 192-198, (2010).

[40] Özdiş, B.E., Çam, N.F. ve Öztürk, B., Assessment of natural radioactivity in cements used as buildingmaterials in Turkey, Journal of Radioanalytical and Nuclear Chemistry, 311, 307-316, (2016).

[41] Belgin, E.E. ve Aycık, G.A., 226Ra, 232Th and 40K Activity concentrations and radiological hazards of building materials in Muğla, Turkey, Mugla Journal of Science and Technology, 1, 2, 11-16, (2015). 
[42] Turhan, S. ve Gürbüz, G., Radiological significance of cement used in building construction in Turkey, Radiation Protection Dosimetry, 129, 4, 391-396, (2008).

[43] Tufan, M.Ç. ve Dişçi, T., Natural radioactivity measurements in building materials used in Samsun, Turkey, Radiation Protection Dosimetry, 156, 1, 8792, (2013).

[44] Damla, N., Çevik, U., Kobya, A.İ., Çelik, A. ve Çelik, N., Assessment of natural radiation exposure levels and mass attenuation coefficients of lime and gypsum samples used in Turkey, Environmental Monitoring and Assessment, 170, 457466, (2010).

[45] Turhan, Ş., Aykamıs, A.S. ve Kılıç A.M., Natural radionuclide content and radiological hazard associated with usage of quartzite sand samples from OvacikSilifke-Mersin open pit as building material in Turkey, Radiation Protection Dosimetry, 136, 2, 101-107 , (2009).

[46] Turhan, Ş., Arıkan, İ.H., Köse, A. ve Varinlioğlu A., Assessment of the radiological impacts of utilizing coal combustion fly ash as main constituent in the production of cement, Environmental Monitoring and Assessment, 177, 14, 555-561, (2011).

[47] Damla, N., Çevik, U., Kobya, A.İ., Çelik, A., Çelik N. ve Van Grieken, R., Radiation dose estimation and mass attenuation coefficients of cement samples used in Turkey, Journal of Hazardous Materials, 176, 1-3, 644-649, (2010).

[48] Turhan, S., Radiological impacts of the usability of clay and kaolin as raw material in manufacturing of structural building materials in Turkey, Journal of Radiological Protection, 29, 1, 75-83, (2009).

[49] Cevik, U., Damla, N., Kobya, A.I., Çelik, N., Çelik, A., Van, A.A., Assessment of natural radioactivity of sand used in Turkey, Journal of Radiological Protection, 29, 1, 61-74, (2009).

[50] Akkurt, I., Oruncak, B. ve Gunoglu, K., Natural Radioactivity and dose rates in commercially used marble from Afyonkarahisar - Turkey, International Journal of the Physical Sciences, 5, 2, 170-173, (2010).

[51] Kam, E. ve Bozkurt, A., Environmental radioactivity measurements in Kastamonu region of northern Turkey, Applied Radiation and Isotopes, 65, 4, 440-444, (2007).

[52] Köksal, E.M., Çelebi, N. ve Özçınar, B., Indoor 222Rn concentrations in İstanbul Houses, Health Physics, 65, 1, 87-88, (1993).

[53] Degerlier, M. ve Çelebi, N., Indoor radon concentrations in Adana, Turkey, Radiation Protection Dosimetry, 131, 2, 259-264, (2008). 